\title{
Review
}

\section{Health relevance of intestinal protein fermentation in young pigs}

\author{
R. Pieper ${ }^{1 *}$, C. Villodre Tudela ${ }^{1,2}$, M. Taciak ${ }^{3}$, J. Bindelle $^{4}$, J. F. Pérez ${ }^{2}$ and \\ J. Zentek ${ }^{1}$ \\ ${ }^{1}$ Department of Veterinary Medicine, Institute of Animal Nutrition, Freie Universität Berlin, \\ Germany \\ ${ }^{2}$ Departament de Ciència Animal i dels Aliments, Universitat Autònoma de Barcelona, 08193 \\ Cerdanyola del Vallès, Barcelona, Spain \\ ${ }^{3}$ The Kielanowski Institute of Animal Physiology and Nutrition, Polish Academy of Sciences, \\ Instytucka 3, 05-110 Jabłonna, Polen \\ ${ }^{4}$ Animal Science Unit, University of Liège, Gembloux Agro-Bio Tech, Passage des Déportés \\ 2, 5030 Gembloux, Belgium
}

\author{
Received 29 January 2016; Accepted 27 May 2016; \\ First published online 30 August 2016
}

\begin{abstract}
The physiological role of the gastrointestinal microbiota has become an important subject of nutrition research in pigs in the past years, and the importance of intestinal microbial activity in the etiology of disease is doubtless. This review summarizes the recent knowledge related to the microbial ecology of protein fermentation and the appearance of protein-derived metabolites along the pig intestine. The amount of fermentable protein depends on factors such as dietary protein concentration, protein digestibility due to secondary or tertiary structure, the interaction with dietary compounds or anti-nutritional factors, and the secretion of endogenous proteins into the gut lumen. High protein diets increase the luminal concentrations and epithelial exposure to putatively toxic metabolites and increase the risk for post-weaning diarrhea, but the mechanisms are not yet clarified. Although the use of fermentable carbohydrates to reduce harmful protein-derived metabolites in pigs is well-established, recent studies suggest that the inclusion of fermentable carbohydrates into diets with low protein digestibility or high dietary protein level may not ameliorate all negative effects with regard to epithelial response. Based on the current knowledge, the use of diets with low levels of high-quality protein may help to reduce the risk for intestinal disease in young pigs.
\end{abstract}

Keywords: protein fermentation, amines, ammonia, short chain fatty acids, pigs, post weaning diarrhea.

\section{Introduction}

The gastrointestinal tract (GIT) of pigs is colonized by a highly diverse microbiota with distinct longitudinal, radial and timely distribution. Within a relatively short time, our knowledge about the pig intestinal microbiota community composition (Kim et al., 2011a; Isaacson and Kim, 2012), the importance of early-life bacterial colonization patterns on immune system

*Corresponding author. E-mail: robert.pieper@fu-berlin.de development (Mulder et al., 2011; Lewis et al., 2012), the composition of the mucosa-associated bacterial communities (Looft et al., 2014; Mann et al., 2014), or the long-term impact of microbial colonization patterns on the metabolic phenotype later in life (Merrifield et al., 2015) has emerged substantially in the past years. A further understanding of the complex interaction of the three-component system nutrition - microbiota host is pivotal to establish successful feeding and management strategies. It is well established that the content of fermentable substrates in pig diets drives the microbial ecology in the GIT and can thereby possibly exert health promoting or detrimental 
effects (Aumiller et al., 2014). The promotion of lactic acid bacteria and short chain fatty acid production (e.g. specifically butyrate) is considered beneficial for the host and may help to maintain a 'balanced' intestinal ecosystem. On the other hand, bacterial protein fermentation taking place mainly in the hindgut, represents a potential risk factor for a compromised intestinal barrier function and increased enteric disease caused by pathogens. However, in pigs, the etiology of diarrhoea associated with higher intestinal protein fermentation is still highly unclear. Understanding the factors influencing intestinal bacterial protein fermentation, the formation of toxic metabolites and subsequent influence on the host is crucial to develop dietary strategies to maintain GIT health. In complement to recent reviews covering parts of this important topic (Rist et al., 2013; Jha and Berrocoso, 2016), the present review will summarize recent advances in the understanding of microbial ecology of protein fermentation and discuss possible consequences for dietary interventions in pigs.

\section{Factors influencing fermentable protein concentration in the gut}

\section{Outbalanced physiological conditions}

External and endogenous factors that can influence protein digestion and absorption under normal and outbalanced physiological conditions along the GIT and some putative consequences for intestinal bacterial protein fermentation are summarized in Table 1. Generally, an efficient pre-caecal protein digestion and absorption is critical for both the supply of the animal with essential amino acids for protein synthesis and a reduced risk of excessive protein fermentation in the large intestine. Under normal physiological conditions, protein digestion begins in the stomach with the initiation of proteolysis through digesta acidification and the autocatalytic activation of pepsin from pepsinogen at low $\mathrm{pH}$. This results in the release of a mix of polypeptides, oligopeptides and some free amino acids. The gastric phase of protein digestion may play only a minor role with regard to total pre-caecal protein digestibility (Erickson and Kim, 1990). As indicated below, there are some indications that dietary (i.e. digesta viscosity, dietary particle size, buffering capacity, antinutritional factors, diet changes) as well as endogenous factors (i.e stress or other hormonal signals affecting gastric emptying rate and feed intake) can lead to conditions that may favor bacterial fermentative activity already in the stomach and the onset of putrefactive fermentation (Table 1). In the small intestine, protein is further digested by pancreatic enzymes and intestinal brush border membrane enzymes to free amino acids and small oligopeptides, which can then be taken up through brush border amino acid transport systems (Ganapathy, 2012). It seems therefore clear that dietary (i.e. digesta viscosity and transit, diet changes, antinutritional factors) or animalderived factors (i.e. gut immaturity at weaning, hormonal signals) or primary enteric infections (e.g. viruses) may interfere with these normal conditions and lead to inflammatory reactions, insufficient enzyme release or activation and endogenous (protein and mucus) secretions (Table 1). An increased flow of undigested protein into the distal parts of the GIT and promotion of bacterial protein fermentation are the logical consequence of these imbalances. In addition, dietary protein levels and fermentability may also favor the growth of specialized proteolytic bacteria (e.g. clostridia). Whether protein fermentation, the promotion of certain bacteria or host inflammatory signals may trigger further bacterial signals (i.e. quorum sensing) and the activation of bacterial pathogenic factors is yet unclear. In the large intestine, non-digested dietary compounds as well as secreted endogenous substrates can be fermented by the indigenous bacteria. As outlined below, the substrate availability is a major driver for bacterial fermentation pathways. An impaired pre-caecal protein digestion and absorption, high dietary protein level in general or higher endogenous secretions will therefore likely increase the amount of fermentable protein entering the large intestine, promote putrefactive fermentation and selective growth of proteolytic bacteria (Table 1). In turn, protein-derived metabolites and dysbioses may interfere with normal physiological conditions of the large intestine such as absorption of bacterial metabolites, electrolytes and fluids as outlined below.

\section{Feed-derived factors influencing protein digestibility}

Knowledge about the undigested protein fractions and their fermentability throughout the different parts of the intestine is still scarce. Usually, protein in animal feed is determined roughly as $N \times 6.25$ and further characterized by the standardized ileal amino acid digestibility, whereas the relationship between structural elements and susceptibility to proteolysis has not been clarified so far. Nonetheless, it is well established that in feedstuffs of lower quality, more undigested dietary proteins will enter the hindgut (Kambashi et al., 2014). Variations observed in individual amino acid digestibility within a feedstuff may be greater than the variation among feedstuffs (Moughan et al., 2014). For example, the quality of fishmeal may vary due to the animal species and tissues used and to the type of processing (Rojas and Stein, 2013). In plant ingredients, the structural properties of proteins may play a major role in the resistance to denaturation and gastrointestinal digestion. For example, the salt-soluble protein content rather than differences on the vitreousness of corn grains provides a better indication of susceptibility of the protein matrix to enzymatic hydrolysis (Gehring et al., 2012). On one hand, the $\beta$-sheet structures of raw legume proteins and the intermolecular $\beta$-sheet aggregates, arising upon heating were highly negatively correlated with feed digestibility values $(r=-0.980)$ (Carbonaro et al., 2012). For soybean and barley seeds, $\beta$-sheet arrangement accounts for at least $30 \%$ of the whole secondary structure. In contrast, animal feed ingredients have a low content of the $\beta$-band: 10.7 and $6.9 \%$ for milk and chicken meat, respectively. The decrease in protein digestibility as dependent on the $\beta$ conformations can be explained by the high hydrophobic character of these structures, which involves aromatic amino acids (phenylalanine, tyrosine, and tryptophan) and $\beta$-branched amino acids (leucine, isoleucine, and valine). Hydrophobic interactions may adversely affect the solubility of vegetable proteins by promoting protein-protein interaction and aggregate 
Table 1. Protein digestion and absorption under normal physiological conditions and factors modulating protein digestion and proteolytic fermentation along the gastrointestinal tract of pigs

\begin{tabular}{|c|c|c|c|c|}
\hline Site of the GIT & Normal physiological conditions & $\begin{array}{l}\text { Outbalanced physiological } \\
\text { conditions }\end{array}$ & Contributing factors & $\begin{array}{l}\text { Consequences for bacterial activity } \\
\text { and metabolites production }\end{array}$ \\
\hline Stomach & $\begin{array}{l}\text { Acidic protein denaturation, } \\
\text { pepsinogen release and } \\
\text { autocatalytic activation through } \\
\text { low pH }\end{array}$ & $\begin{array}{l}\text { Reduced gastric emptying rate, gastric } \\
\text { ulcers, limited digesta acidification, } \\
\text { reduced proteolysis, reduced mucus } \\
\text { secretion }\end{array}$ & $\begin{array}{l}\text { High viscosity, reduced feed intake, } \\
\text { stress, sudden dietary changes, } \\
\text { endocrine signals, feed particle size } \\
\text { (e.g. small particles), high buffering } \\
\text { capacity of the feed (e.g. minerals, } \\
\text { protein level), antinutritional factors } \\
\text { (e.g. tannins, phytate, lectins) }\end{array}$ & $\begin{array}{l}\text { Bacterial fermentative activity } \uparrow \\
\text { Organic acids } \uparrow \text { Activation of } \\
\text { bacterial amino acid deaminase and } \\
\text { decarboxylase systems Ammonia } \uparrow \\
\text { Biogenic amines } \uparrow \text { (nitrosation } \\
\text { reactions) }\end{array}$ \\
\hline Small intestine & $\begin{array}{l}\text { Digesta alkalization, pancreatic } \\
\text { proenzyme release and } \\
\text { activation (trypsin, chymotrypsin, } \\
\text { elastase, carboxypeptidases, } \\
\text { proteases), brush border } \\
\text { peptidases (endo-, amino-, } \\
\text { carboxy-, di-), amino acid and } \\
\text { small peptide absorption by } \\
\text { enterocytes some bacterial } \\
\text { amino acid synthesis }\end{array}$ & $\begin{array}{l}\text { Exocrine pancreatic insufficiency, } \\
\text { reduced activity of digestive } \\
\text { enzymes, inflammatory processes, } \\
\text { excessive endogenous (mucus) } \\
\text { secretions }\end{array}$ & $\begin{array}{l}\text { Reduced digesta transit (e.g. high } \\
\text { viscosity and NSP), gut hormones, } \\
\text { gut immaturity, antinutritional } \\
\text { factors (e.g. protease inhibitors, } \\
\text { lectins), weaning stress, dietary } \\
\text { changes and composition, primary } \\
\text { enteric infections (e.g. viruses) }\end{array}$ & $\begin{array}{l}\text { Bacterial fermentative activity } \uparrow \\
\text { Ammonia } \uparrow \text { Biogenic amines } \uparrow \\
\text { Proliferation of proteolytic bacteria } \\
\text { Bacterial toxins and LPS } \uparrow \text { Sulfur } \\
\text { metabolism, } \mathrm{H}_{2} \mathrm{~S} \text { production } \uparrow\end{array}$ \\
\hline Large intestine & $\begin{array}{l}\text { Acidic } \mathrm{pH} \text {, Intense carbohydrate } \\
\text { fermentation, production and } \\
\text { absorption of SCFA, bacterial } \\
\text { amino acid and protein synthesis } \\
\text { and lysis of endogenous and } \\
\text { dietary protein (distal colon) fluid } \\
\text { and electrolyte absorption,final } \\
\text { condensation of digesta (distal } \\
\text { colon) }\end{array}$ & $\begin{array}{l}\text { Neutral or alkaline } \mathrm{pH} \text {, inflammatory } \\
\text { processes, malabsorption of organic } \\
\text { acids, electrolytes and fluids, } \\
\text { dysbiosis }\end{array}$ & $\begin{array}{l}\text { Low level of dietary fiber, high dietary } \\
\text { protein level, high level of } \\
\text { indigestible protein, small intestinal } \\
\text { maldigestion and/or malabsorption, } \\
\text { high secretion of endogenous } \\
\text { protein in proximal GIT }\end{array}$ & $\begin{array}{l}\text { Proteolysis } \uparrow \text { Bacterial amino acid } \\
\text { fermentative activity } \uparrow \\
\text { Accumulation of organic acids } \\
\text { Ammonia } \uparrow \text { Biogenic amines } \\
\uparrow \text { Phenolic compounds } \uparrow \\
\text { Proliferation of proteolytic bacteria } \\
\text { (e.g. some clostridia) Bacterial toxins } \\
\text { and LPS } \uparrow \text { Sulfur metabolism, } \mathrm{H}_{2} \mathrm{~S} \\
\text { production } \uparrow \text { (nitrosation reactions) }\end{array}$ \\
\hline
\end{tabular}


formation likely reducing accessibility of susceptible sites to proteases (Carbonaro et al., 1993, 1997). On the other hand, the presence of random coil or unordered secondary structures in animal food proteins has been related to the increment in digestibility.

Differences in protein digestibility have also been related to the interaction of protein with dietary heat-stable (phytic acid, tannins, calcium, non-starch polysaccharides) and heat-labile compounds (protease inhibitors and lectins). It is generally accepted that the negatively charged phytate molecules may form binary, salt-like protein-phytate complexes with proteins carrying a net positive charge, or unhindered basic amino acid residues at the outer surface of the protein, at a $\mathrm{pH}$ lower than their isoelectric point (Cosgrove, 1966). The protein molecules become closely packed around the phytate anion forming insoluble aggregates (Rajendran and Prakash, 1993) that are refractory to pepsin digestion (Knuckles et al., 1989). At a pH above their isoelectric point, proteins carrying a net negative charge may establish cationic bridges (usually $\mathrm{Ca}^{2+}$ ) with phytate molecules in ternary complexes. However, it is generally accepted that ternary complexes are not as important as binary complexes in respect of phytate-reducing protein availability (Selle et al., 2012). The negative ionic properties of phytate may also indirectly stabilize proteins and reduce their solubility mainly by changing the hydrogen-bonding properties of water in the surrounding medium.

Processing of feedstuffs such as soy meal improves its digestibility and inactivates protease inhibitors, but may also damage several amino acids (e.g. lysine, arginine, methionine, cysteine, and tryptophan) (González-Vega et al., 2011). Protein-bound lysine and free lysine, both having an epsilon amino group, can react with reducing sugars in Maillard reactions, fats and their oxidation products, polyphenols, and various dietary additives. In particular, the reaction between lysine and reducing sugars may take place under mild conditions of processing to form the deoxy-ketosyl derivative (the Amadori compound), while it may induce a brown pigment formation at advanced stages of Maillard reactions when lysine is completely altered. The Amadori compound may be reverted by the hydrochloric acid hydrolysis during amino acid analysis, but reversion does not occur under the milder conditions encountered in the pig digestive tract (Moughan et al., 2014). Based on reactive lysine analyses, Fontaine et al. (2007) characterized different soybean meal and dried distillers grains with solubles (DDGS) samples, and determined that $10-20 \%$ lysine damage is typical for normal soybean meals and that overheated batches had lost up to $67 \%$ of the reactive lysine.

As indicated, the secreted endogenous proteins may also contribute to the flow of undigested protein into the hindgut. Endogenous protein is considered to consist of two components: a basal endogenous flow, which is related to food dry matter intake, and a dietary-variable flow, referred to as the specific endogenous protein loss (Stein et al., 2007). The specific loss is affected by dietary factors such as type and concentration of fiber and the level of various antinutritional factors (e.g. trypsin inhibitor, tannins, lectins, phytate). Cellulose, lignin, arabinoxylans and pectin can increase the sloughing of intestinal mucosal cells and enhance viscosity of digesta and mucus production (De Lange et al., 1989; Choct and Annison, 1992). Thus, it is likely that the inclusion of dietary fiber into pig diets will also increase the flow of undigested endogenous proteins to the large intestine (Souffrant, 2001).

\section{Bacterial protein fermentation in the gastrointestinal tract}

Bacterial amino acid metabolism occurs via oxidative and reductive reactions including deamination, decarboxylation, and alpha and beta-elimination. Deaminases are more active at neutral or even slightly alkaline $\mathrm{pH}$, whereas decarboxylase activity is higher under acidic conditions (Blachier et al., 2007). Thus, bacterial protein catabolism is closely related to $\mathrm{pH}$ and the availability of fermentable carbohydrates (Smith and MacFarlane, 1998; Davila et al., 2013). In the GIT of the pig, the continuous digestion and bacterial fermentation of carbohydrates favors the metabolic shift of the microbiota from the extracellular hydrolysis of protein into amino acids and peptides for further incorporation in bacterial cells towards true amino acid fermentation for energy metabolism in the distal colon, where the $\mathrm{pH}$ again increases above 6 as a consequence of the release of alkaline ammonia. However, as indicated above (Table 1), bacterial protein fermentation may not be limited to the large intestine and can also occur to some extent in the proximal GIT. The major amino acid fermenting bacteria in the GIT include proteolytic members of Fusobacteria, Firmicutes (Streptococcaceae, Veillonellaceae, Megasphera, Selenomonas), Proteobacteria, and Bacteroidetes (Dai et al., 2011). This comprises a large variety of phylogenetically distinct species but includes also putatively pathogenic species such as E. coli, Klebsiella spp., Campylobacter spp., Streptococcus spp., C. perfringens, C. difficile or Bacteroides fragilis, and may partly explain why high protein diets in pigs have been associated with gastrointestinal dysbioses and diarrhea (Ball and Aherne, 1987; Wellock et al., 2008; Opapeju et al., 2009).

Deamination of amino acids leads to formation of ammonia and the remaining carbon skeleton can be further metabolized to yield short chain fatty acids (SCFAs) and branched chain fatty acids (BCFAs) from branched chain amino acids. Thus, bacterial amino acid utilization also contributes to considerable amounts of acetate (e.g. from alanine, aspartate, glycine, threonine, lysine), propionate (e.g. from alanine, threonine) and butyrate (from lysine, glutamate). BCFAs are formed by deamination reaction from branched chain amino acids such as valine (isobutyrate), isoleucine (2-methylbutyrate) and leucine (isovalerate) and are thus indicators of microbial amino acid metabolism. Decarboxylation of amino acids yields several biogenic amines and occurs usually at a $\mathrm{pH}$ between 4 and 6 . Examples for typical amines are cadaverine (lysine), histamine (histidine), tyramine (tyrosine), tryptamine (tryptophane), ethylamine (alanine) or agmatine (aspartate). Polyamines, which can be found in higher concentrations in the large intestine, include mainly putrescine, spermine and spermidine. Obviously, the decarboxylation (and to some extent also the deamination) of amino acids in the pig intestinal tract can already occur in the small 
intestine (Table 1). For example, increased concentrations of ammonia and biogenic amines can already be found in the stomach and ileum of pigs (Pieper et al., 2014). The production of amines such as cadaverine, in turn, reflects a bacterial adaptation in order to buffer a low $\mathrm{pH}$ under high concentration of SCFA and lactate (Pieper et al., 2014). Lysine decarboxylase positive bacteria can increase cadaverine production under co-cultivation conditions with lactic acid bacteria (Kuley et al., 2012). Amines also act as precursors for $N$-nitrosation but little is yet known about the formation of nitrosamines and their pathophysiological function in the pig gut. Many intestinal bacteria (including bifidobacteria, lactobacilli, and enterobacteria) are capable of reducing nitrate to nitrite as prerequisite for nitrosation reactions. Using an in vitro model of the pig cecum, it was shown that nitrate reduction was accompanied with $\mathrm{N}$-nitrosamine production (Engemann et al., 2013). Since nitrosamine formation occurs under low $\mathrm{pH}$, a higher production of these compounds may also take place in the stomach.

A number of phenolic and indolic compounds may also be produced from the metabolism of aromatic amino acids (Blachier et al., 2007; Davila et al., 2013). Tyrosine leads to the formation of 4-ethylphenol, phenol and p-cresol, whereas tryptophane is metabolized to indole, skatole (3-methylindole) (Blachier et al., 2007). Urinary metabolomic profiles of germfree and conventionally colonized rats were largely different and in conventional rats characterized by products from tryptophane and tyrosine metabolism indicating the profound role of the GIT microbiota in phenol and indole formation (Wikoff et al., 2009).

Finally, sulfur-containing amino acids and intestinal sulfomucins are converted to a number of sulfur containing metabolites including hydrogen sulphide, methanethiol and dimethyltrisulphide (Geypens et al., 1997). A broad range of different bacterial species including Clostridiales, Bacteroides, Prevotella, Enterobacteriaceae or Streptococcaceae have been identified for their role in metabolism of sulphur containing substrates such as methionine, cysteine, taurine, sulfomucins and bile acids in the intestine (Carbonero et al., 2012). Sulfate reducing bacteria were identified to play a major role in $\mathrm{H}_{2} \mathrm{~S}$ formation in the pig, with the genus Desulfovibrio being the most important.

\section{Host response to microbial fermentation products}

\section{Short chain fatty acids}

Generally, SCFA (derived from carbohydrate or protein fermentation) are rapidly absorbed from the gut lumen and serve as energy substrates. Acetate acts mainly as precursor for fatty acids synthesis, whereas propionate is mainly used for gluconeogenesis in the liver. Butyrate, in turn, is mainly metabolized by epithelial cells and has been proposed as the main energy source for colonocytes (Hamer et al., 2008). In the pig, the utilization of SCFA can contribute considerably to the daily energy supply depending on the diet and the physiological status of the animal, adults being more able to extract energy from intestinal fermentation than young pigs (Kambashi et al., 2014). In addition,
SCFA stimulate epithelial proliferation and barrier function, and modulate immune response and satiety through receptor mediated signaling (Hamer et al., 2008; Willing and Van Kessel, 2010). For example, the monocarboxylate transporter 1 (MCT1) can be stimulated by butyrate leading to increased butyrate uptake (Borthakur et al., 2012). The entire mechanism is yet not clear but as butyrate is an important energy source for colonocytes, both stimulation and inhibition of MCT1 may have important health implications. Interestingly, the pro-inflammatory cytokine TNF- $\alpha$ reduced MCT1 expression and impaired butyrate uptake (Villodre Tudela et al., 2015). SCFAs have been shown to improve epithelial barrier function, which has been attributed - at least in part - to higher expression of tight junction proteins ZO-1 and occludin through butyrate-induced signaling cascades (Plöger et al., 2012). On the other hand, TNF- $\alpha$ and other pro-inflammatory cytokines can decrease barrier function through reduced claudin- 1 and 2 expression (Plöger et al., 2012). SFCA also influence mucus production by goblet cells: propionate directly increases MUC2 expression through a SCFA-responsive regulatory element, whereas butyrate regulates gene expression via effects on histone acetylation (Burger-van Paassen et al., 2009). Propionate, acetate, and to a lesser extent butyrate, can act as signaling molecules through free fatty acid receptors (FFAs) such as FFA2R (GPR43) or FFA3R (GPR41) (Ulven, 2012). The FFA2R is highly expressed in neutrophils, macrophages and monocytes and SCFA have been shown to promote neutrophil chemotaxis through this receptor (Vinolo et al., 2011). Both, FFA2R and FFA3R have been associated with activation of mitogenactivated protein kinase (MAPK) signaling and pro-inflammatory cytokine expression in mice (Kim et al., 2013). Both receptors are also expressed in large intestinal enteroendocrine cells, which release peptide YY and glucagon-like peptide-1 (GLP-1). Whereas PYY reduces gastric emptying and increases satiety, GLP-1 (and the co-released GLP-2) promotes small intestinal proliferation and improves barrier function (Liu et al., 2013). This could be also interpreted as reversed large to small intestinal signaling, as reduced feed intake and gastric emptying accompanied with increased absorptive capacity in the small intestine would reduce large intestinal SCFA concentrations. Finally, it has been hypothesized that the excessive production of SCFA is causative for intestinal inflammation and the onset of necrotizing enterocolitis in young piglets (Di Lorenzo et al., 1995; Lin, 2004). Thus, positive effects of SCFA on intestinal epithelia seem to be dose- and also age-dependent.

\section{Biogenic amines}

Biogenic amines have several effects on the host. Polyamines can be either produced by bacteria in the GIT or synthetized by colonocytes through ornithine decarboxylase. The role of polyamines such as spermidine, spermine and putrescine has been studied in detail due to their enhancing effect on cell proliferation (Seiler and Raul, 2007). However, studies in gnotobiotic rats did not reveal any significant in vivo effects of bacteria-derived polyamines on intestinal morphology (Slezak 
et al., 2013). Amines are rapidly absorbed from the intestine and either further metabolized in the epithelium via specific monoor diamine oxidase and excreted via urine (Hughes et al., 2000). For example, histamine has several biological functions including induction of chloride secretion into the gut lumen, which may promote diarrhea (Ahrens et al., 2003). Histamine is derived from exogenous L-histidine or released endogenously by mast cells and is metabolized by diamine oxidase and histamine $N$-methytransferase in the colon epithelium (Aschenbach et al., 2009). Higher concentration of luminal histamine increased the epithelial capacity to metabolize this compound in the pig colon (Kröger et al., 2013). Little is yet known about the role of other biogenic amines. Cadaverine and putrescine may reduce the metabolism of histamine in the epithelium as both are also converted by diamine oxidase, thus possibly enhancing negative effect of histamine. Although speculative, this may explain why increased incidence of diarrhea was associated with high intestinal concentrations of amines such as cadaverine and putrescine (Pietrzak et al., 2002). There might also be a link between lysine decarboxylation to cadaverine and pathogenicity of E. coli and Salmonella. For example, the absence of the responsible cadA gene, which encodes L-lysine decarboxylase, dramatically increases enterobacterial virulence (Torres, 2009). Whether cadaverine itself can provide feedback signals influencing the expression of pathogenic factors is yet not clear. Finally, as indicated above, little is yet known about the formation and function of nitrosamines in the pig gut.

\section{Ammonia}

Protein fermentation products such as ammonia have been primarily associated with toxigenic and damaging effects on the intestinal epithelium in human beings (Blaut and Clavel, 2007; Davila et al., 2013). Ammonia can interfere with the oxidative metabolism of SCFA in colonocytes, likely inducing energy deficiency in the cell (Blachier et al., 2007). Moreover, increased apoptosis and higher proliferation may occur through activation of caspases and mitosis, respectively (Blachier et al., 2007; Willing and Van Kessel, 2010). Whether this is due to direct toxigenic effect on the cells or mediated through specific receptors is not yet clear. In human beings, higher ammonia concentrations in the distal colon have been associated with tumor promotion (Hughes et al., 2000; Blaut and Clavel, 2007). Recent results suggest that ammonia and other protein-derived metabolites present in the lumen may entail inflammatory responses in the colonic mucosa, which negatively influence the expression of MCT1 (Villodre Tudela et al., 2015). Ammonia and BCFA impaired barrier function and promoted pro-inflammatory signaling expression through NFkB-mediated signaling in Caco-2 cells, and the co-incubation with butyrate did not ameliorate these reactions (Villodre Tudela et al., 2016). This may provide an interesting link between impaired protective effects of butyrate on the colon epithelium and pro-inflammatory conditions in the colon when high concentrations of ammonia are present. In addition, ammonia increased permeability towards macromolecules in Caco-2 monolayers (Hughes et al., 2008). Upon absorption, ammonia is mainly detoxified in the liver to urea and plasma urea nitrogen can be used to some extent to assess the degree of intestinal protein degradation in pigs fed diets with balanced amino acid profile. In turn, higher plasma urea levels were associated with increased urea flux from the serosal to the mucosal site in pig cecum and this effect was related to cecal luminal SCFA levels as compensatory $\mathrm{pH}$-dependent mechanism (Stumpff et al., 2013). Although yet not clearly established, this may have implications when higher levels of SCFA (e.g. by feeding higher levels of non-digestible carbohydrates) are present in the gut lumen, as transports of urea into the gut lumen will in turn increase toxic ammonia levels.

\section{Hydrogen sulphide}

Hydrogen sulphide is a toxic gas and has been attributed to both beneficial and deleterious effects in the intestine (Blachier et al., 2010). High intestinal concentrations have been considered detrimental for the host due to its effect on cell respiration and genomic DNA damage (Davila et al., 2013). $\mathrm{H}_{2} \mathrm{~S}$ can inhibit butyrate $\beta$-oxidation in human epithelial colonic cells by inhibition of short chain acyl-CoA dehydrogenase activity as well as glutamine and acetate oxidation (Leschelle et al., 2002). In addition, $\mathrm{NaHS}$ can stimulate chloride secretion in isolated colonic tissue of pigs (Kröger et al., 2013). On the other hand, $\mathrm{H}_{2} \mathrm{~S}$ at lower concentrations is also considered as a signaling molecule associated with physiological and pathophysiological functions including inhibition of insulin secretion, vasoconstrictive effects as well as effects on mononuclear cell infiltration (Blachier et al., 2010; Wallace et al., 2012). Thus, the positive or detrimental effects of hydrogen sulphide on intestinal epithelial cells seem to be largely dose-dependent.

\section{Phenolic compounds}

Upon absorption in the large intestine (as the main site of phenol and indole formation), phenolic compounds are detoxified through glucuronidation and sulfate conjugation and excreted via urine, mainly as $p$-cresol. Thus, total phenol and $p$-cresol in urine, besides their concentration in the large intestinal digesta, can serve as markers for increased intestinal amino acids catabolism (Geypens et al., 1997). Phenol has been shown to increase epithelial permeability (Hughes et al., 2008). In the GIT, phenols might be involved in $N$-nitrosation of dimethylamine, and reaction with nitrite produces the toxic metabolites, p-nitrosophenol and diazoquinone (Kikugawa and Kato, 1988). Finally, from a consumers point of view, the role of 3-methylindole (skatole) is of high importance in intact male pigs as it is involved in boar taint' of the meat (Jensen et al., 1995).

\section{The role of protein fermentation in diarrhea in pigs}

It is well established for decades that increased protein fermentation in the GIT can lead to intestinal disorders including post- 
weaning diarrhea (PWD). In fact, it has already been reported $>35$ years ago that diets high in protein $(21$ versus $13 \% \mathrm{CP}$ ) predispose for enteropathogenic E.coli infections and diarrhea in piglets (Prohaszka and Baron, 1980). The etiology and mechanisms behind this are not entirely clear. Table 2 summarizes some putative factors related to bacterial protein utilization that may contribute to different types of pathophysiological conditions and diarrhea in pigs. It has been previously assumed that a higher protein level may change the buffering capacity in the stomach, thereby reducing the gastric barrier and favoring the proliferation of enterobacteria or clostridia (Prohaszka and Baron, 1980). This effect may be further amplified through a lower gastric acid production due to (weaning) stress. Although not clearly established, the hygienic quality of the feed might be considered as additional factor. It has been assumed that protein fermentation may selectively favor the growth of enteropathogenic E. coli (Rist et al., 2013). However, E. coli-induced secretory diarrhea affects mainly the small intestine (Fairbrother et al., 2005), whereas the site of excessive microbial protein fermentation is usually the large intestine. Protein-derived metabolites formed by other proteolytic bacteria such as clostridia may also induce impaired barrier function through altered mucus composition and tight junctions, thereby favoring the translocation of enterobacteria as secondary opportunists. Although not directly related to bacterial protein fermentation, foreign proteins of plant origin (e.g. legumes) can induce small intestinal epithelial damage due to overwhelming immune reactions and episodes of diarrhea (Stokes et al., 1987). Large intestinal epithelial damage by protein-derived metabolites or bacterial toxins may reduce the ability for fluid re-absorption, which otherwise could mask small intestinal hyper-secretion (Table 2). Interestingly, diets high in fermentable protein reduced the activity of the large intestinal epithelial ameloride-sensitive sodium channel $\mathrm{ENaC}$, which was associated with more liquid feces in piglets (Richter et al., 2014). Indirect effects of protein-derived metabolites include higher formation of histamine, which contribute to increased chloride secretion and fluid loss into the large intestinal lumen through receptor-mediated signaling (Kröger et al., 2013, 2015). Other factors such as digesta viscosity or digesta transit may promote the ability of enterobacteria to adhere to specific mucus motifs in the small intestine. Intestinal metabolites or bacterial quorum sensing molecules may also induce the expression of virulence factors in enterobacteria, which has yet not been studied in detail.

It has been proposed that the dietary protein level rather than the protein source may predispose piglets to intestinal diseases (Rist et al., 2013). This is in good agreement with a recent between-experiment study showing that fecal ammonia concentration and blood urea levels were increased with higher dietary protein levels and, in turn, increased the incidence of PWD (Heo et al., 2015). Thus, a common strategy to reduce the risk of PWD is through a low $(<18 \%)$ dietary protein level or total daily intake of less than $60 \mathrm{~g}$ (Heo et al., 2012, 2015). Feeding such low $(13 \%)$ versus high $(23 \%)$ protein diets may also increase the fecal lactobacilli to enterobacteria ratio (Wellock et al., 2006). However, other studies showed no effect of protein level on the number of different microbial groups
(Bikker et al., 2006; Nyachoti et al., 2006; Hermes et al., 2009). As indicated above, numerous different types of bacteria are able to utilize dietary and endogenous protein sources and thus the measured response in terms of bacterial counts can vary widely. Diets low in dietary protein have been associated with reduced incidence of diarrhea in ETEC challenged and non-challenged piglets (Heo et al., 2008, 2009; Opapeju et al., 2009; Kim et al., 2011b). In turn, lower protein levels were accompanied with increased levels of bacterial species (Roseburia/E. rectale-like), which are specialized for carbohydrate utilization and butyrate formation (Opapeju et al., 2009). Although no differences in total SCFA were observed in this study, it shows that a low protein level and likely also the flow of fermentable carbohydrates may beneficially affect the large intestinal environment.

Intestinal bacteria may switch between complete or partial utilization of carbohydrates and protein (amino acids) as substrates to derive energy. Thus, dietary inclusion of a variety of fermentable carbohydrates may be a promising approach to reduce harmful protein fermentation in the porcine GIT. The fermentation of these carbohydrates induces a shift on nitrogen excretion from urine to feces (Bindelle et al., 2007, 2009; Jha and Berrocoso, 2016). In fact, inulin, resistant starch, cereal fibers and sugar beet pulp have been shown to decrease the abundance of protein fermentation products (Awati et al, 2006; Bikker et al., 2006; Nyachoti et al., 2006; Pieper et al., 2012, 2014). However, although the effects of fiber inclusion on bacterial metabolites in high protein diets were often statistically significant, the concentration of toxic metabolites such as ammonia was by far not reduced to similar levels as with low protein diets. For example, although dietary carbohydrate inclusion (wheat bran, SBP) reduced the formation of intestinal protein-derived metabolites in the large intestine of piglets, blood urea nitrogen was higher in high protein diets regardless of carbohydrate level (Pieper et al., 2012; Stumpff et al., 2013). In addition, the expression of pro-inflammatory cytokines, mucus genes and oxidative stress indicators was largely unaffected by dietary carbohydrate level and increased with protein level in the colon epithelium (Pieper et al., 2012). Linking the site of dietary protein fermentation with the effectiveness of different carbohydrate sources (insoluble, partly soluble), it was shown that SBP mainly increased SCFA and lactate and decreased protein-derived metabolites in the large intestine, whereas cellulose was partly fermented in the distal large intestine and reduced mainly phenols, indoles and cadaverine, but not ammonia (Pieper et al., 2014). This may have health relevance as it was recently shown that protein-derived metabolites (i.e. ammonia, putrescine) were negatively correlated with the MCT1 gene expression in the intestine of pigs (Villodre Tudela et al., 2015). The MCT1 expression was reduced in high protein diets regardless of dietary carbohydrate inclusion. Further analyses revealed that ammonia (through TNF- $\alpha$-mediated signaling) leads to a down-regulation of the MCT1 gene linking impaired protective effects of butyrate and pro-inflammatory conditions in the colon of pigs. This raises the question about optimum inclusion levels of different types of fermentable carbohydrate sources that direct microbial fermentation patterns towards carbohydrates 
Table 2. Pathophysiological conditions leading to diarrhea and their putative relation to bacterial protein utilization in different parts of the porcine GIT

\begin{tabular}{|c|c|c|c|c|}
\hline Site & $\begin{array}{l}\text { Pathophysiological } \\
\text { reactions }\end{array}$ & Cause & Consequence & $\begin{array}{l}\text { Putative relation to dietary protein and } \\
\text { bacterial protein fermentation }\end{array}$ \\
\hline Stomach & $\begin{array}{l}\text { Low acidification, } \\
\text { inflammatory } \\
\text { reactions (?) }\end{array}$ & $\begin{array}{l}\text { Buffering capacity of the feed, secretory } \\
\text { dysfunction, overload with feed, stress or } \\
\text { interfering diseases (?), spoiled feedstuff } \\
\text { (protein sources) }\end{array}$ & $\begin{array}{l}\text { Bacterial overgrowth, insufficient } \\
\text { inactivation of exogenous bacteria (feed } \\
\text { pathogens), inflammatory reactions }\end{array}$ & $\begin{array}{l}\text { Pathogen intrusion in the small intestine, } \\
\text { feed poisoning, bacterial toxins and } \\
\text { metabolites (e.g. biogenic amines) }\end{array}$ \\
\hline \multirow[t]{3}{*}{ Small intestine } & Hypersecretory & $\begin{array}{l}\text { Bacterial toxins (e.g. E.coli, Shigella toxins), } \\
\text { viral infections, biogenic amine } \\
\text { production (histamine), tissue damage } \\
\text { and inflammation }\end{array}$ & $\begin{array}{l}\text { Fluid, chloride, sodium, } \mathrm{HCO}_{3} \text { secretion, } \\
\text { motoric dysfunction }\end{array}$ & $\begin{array}{l}\text { Selective growth of toxin producing } \\
\text { strains, toxin activation (?), overgrowth } \\
\text { and translocation of secondary } \\
\text { opportunistic bacteria, protein-derived } \\
\text { metabolites (e.g. ammonia, biogenic } \\
\text { amines) } \uparrow\end{array}$ \\
\hline & Hyperosmotic & Lactose, minerals & High fluid secretion and net fluid losses & $\begin{array}{l}\text { Proteolysis and protein digestibility in } \mathrm{SI} \downarrow \\
\text { Fermentable protein entering the large } \\
\text { intestine } \uparrow\end{array}$ \\
\hline & $\begin{array}{l}\text { Hypersensitivity to } \\
\text { allergens }\end{array}$ & Legumes, eg. glycinin, conglycinin & $\begin{array}{l}\text { Leucocyte infiltration, cytokine release } \\
\text { and inflammatory reactions, impaired } \\
\text { barrier function, hypersecretory reactions }\end{array}$ & Direct (foreign/antigenic) protein effect \\
\hline \multirow[t]{3}{*}{ Large intestine } & Hypersecretory & $\begin{array}{l}\text { Bacterial toxins (e.g. C. perfringens, } \\
\text { Salmonella), viral infections, protozoans/ } \\
\text { metazoans, biogenic amine production } \\
\text { (histamine), tissue damage and } \\
\text { inflammation }\end{array}$ & $\begin{array}{l}\text { Fluid, chloride, sodium, } \mathrm{HCO}_{3} \text { secretion, } \\
\text { motoric dysfunction }\end{array}$ & $\begin{array}{l}\text { Selective growth of toxin producing } \\
\text { strains, Toxin activation (?), } \\
\text { protein-derived metabolites (e.g. } \\
\text { ammonia, biogenic amines) }\end{array}$ \\
\hline & Hyperosmotic & organic acid accumulation & High fluid secretion and net fluid losses & $\begin{array}{l}\text { Excessive fermentation of easily accessible } \\
\text { substrates (low SI digestibility) }\end{array}$ \\
\hline & Malabsorption & $\begin{array}{l}\text { Dysfunction or limited capacity of } \\
\text { epithelial sodium channels }\end{array}$ & Fluid malabsorption & $\begin{array}{l}\text { indirect through cytokine signaling and } \\
\text { protein-induced inflammatory reactions }\end{array}$ \\
\hline
\end{tabular}


and promote bacterial biomass formation along the entire GIT (Pieper et al., 2015). As an example, the addition of non-starch polysaccharides to diets containing resistant starch shifted the site of starch and fiber fermentation towards more distal parts of the colon (Govers et al., 1999). Otherwise, even at high inclusion rates of fermentable carbohydrates, it seems that protein fermentation is not sufficiently reduced or just shifted distally without protective effects on intestinal functionality.

\section{Summary and outlook}

The porcine GIT is colonized by a highly diverse microbial community, which is increasingly recognized for its role in nutrient utilization and influence on host health. Our understanding of this ecosystem has emerged during the past years but some aspects including the complex nutrition - microbe host interactions have yet received less attention. New concepts related to the mucosal microbiota and bacterial functionality rather than studying the community composition in general may gain more attention in the near future. Targeting the intestinal microbial ecosystem by means of nutritional manipulation offers great potential to maintain gut health. Fermentation of undigested proteins may impair epithelial functionality and set the scene for intestinal disorders through a variety of toxic metabolites. Reducing the dietary protein content, inclusion of different types of fermentable fiber and choice of highly digestible protein sources are likely to limit negative effects of bacterial protein fermentation. The interaction of protein and fiber fermentation along the intestinal tract and the influence on the host have still to be defined further in order to formulate appropriate 'healthy' pig diets.

\section{Acknowledgments}

This review was supported by the European Union through COST Action FA1401.

\section{References}

Ahrens R, Gäbel G, Garz B and Aschenbach JR (2003). Histamineinduced chloride secretion is mediated via $\mathrm{H} 2$-receptors in the pig proximal colon. Inflammation Research 52: 79-85.

Aschenbach JR, Honscha KU, von Vietinghoff V and Gäbel G (2009). Bioelimination of histamine in epithelia of the porcine proximal colon of pigs. Inflammation Research 58: 269-276.

Aumiller T, Mosenthin R and Weiss E (2014). Potential of cereal grains and grain legumes in modulating pig's intestinal microbiota-A review. Livestock Science 172: 16-32.

Awati A, Williams BA, Bosch MW, Gerrits WJJ and Verstegen MWA (2006). Effect of inclusion of fermentable carbohydrates in the diet on fermentation end-product profile in feces of weanling piglets. Journal of Animal Science 84: 2133-2140.

Ball RO and Aherne FX (1987). Influence of dietary nutrient density, level of feed intake and weaning age on young pigs. II. Apparent nutrient digestibility and incidence and severity of diarrhea. Canadian Journal of Animal Science 67: 1105-1115.
Bikker P, Dirkzwager A, Fledderus J, Trevisi P, le Huerou-Luron I, Lalles JP and Awati A (2006). The effect of dietary protein and fermentable carbohydrates levels on growth performance and intestinal characteristics in newly weaned piglets. Journal of Animal Science 84: 3337-3345.

Bindelle J, Buldgen A, Michaux D, Wavreille J, Destain JP and Leterme P (2007). Influence of purified dietary fibre on bacterial protein synthesis in the large intestine of pigs, as measured by the gas production technique. Livestock Science 109: 232-235.

Bindelle J, Buldgen A, Delacollette M, Wavreille J, Agneessens R, Destain JP and Leterme P (2009). Influence of source and concentrations of dietary fiber on in vivo nitrogen excretion pathways in pigs as reflected by in vitro fermentation and nitrogen incorporation by fecal bacteria. Journal of Animal Science 87: 583-593.

Blachier F, Mariotti F, Huneau JF and Tomé D (2007). Effects of amino acid-derived luminal metabolites on the colonic epithelium and physiopathological consequences. Amino Acids 33: 547-562.

Blachier F, Davila AM, Mimoun S, Benetti PH, Atanasiu C, Andriamihaja M, Benamouzig R, Bouillaud F and Tomé D (2010). Luminal sulfide and large intestine mucosa: friend or foe? Amino Acids 39: 335-347.

Blaut M and Clavel T (2007). Metabolic diversity of the intestinal microbiota: implication for health and disease. Journal of Nutrition 137: $751-755$.

Borthakur A, Priyamvada S, Kumar A, Natarajan AA, Gill RK, Alrefai WA and Dudeja PK (2012). A novel nutrient sensing mechanism underlies substrate-induced regulation of monocarboxylate transporter-1. American Journal of Gastrointestinal and Liver Physiology 303: 1126-1133.

Burger-van Paassen N, Vincent A, Puiman P, Van Der Sluis M, Bouma J, Boehm G, van Goudoever JB, van Seuningen I and Renes I (2009). The regulation of intestinal mucin MUC2 expression by short-chain fatty acids: implications for epithelial protection. Biochemical Journal 420: 211-219.

Carbonaro M, Vecchini P and Carnovale E (1993). Protein solubility of raw and cooked beans (Phaseolus vulgaris): role of the basic residues. Journal of Agricultural and Food Chemistry 41: 1169-1175.

Carbonaro M, Cappelloni M, Nicoli S, Lucarini M and Carnovale E (1997). Solubility-digestibility relationship of legume proteins. Journal of Agricultural and Food Chemistry 45: 3387-3394.

Carbonaro M, Maselli P and Nucara A (2012). Relationship between digestibility and secondary structure of raw and thermally treated legume proteins: a Fourier transform infrared (FT-IR) spectroscopic study. Amino Acids 43: 911-921.

Carbonero F, Benefiel AC, Alizadeh-Ghamsari AH and Gaskins HR (2012). Microbial pathways in colonic sulphur metabolism and links with health and disease. Frontiers in Physiology 3: 448.

Choct M and Annison G (1992). Anti-nutritive effect of wheat pentosans in broiler chickens: roles of viscosity and gut microflora. British Poultry Science 33: 821-834.

Cosgrove DJ (1966). The chemistry and biochemistry of inositol polyphosphates. Reviews of Pure and Applied Chemistry 16: 209-224.

Dai ZL, Wu G and Zhu WY (2011). Amino acid metabolism in intestinal bacteria: links between gut ecology and host health. Frontiers in Bioscience 16: 1768-1786.

Davila AM, Blachier F, Gotteland M, Andriamihaja M, Benetti PH, Sanz Y and Tomé D (2013). Intestinal luminal nitrogen metabolism: role of the gut microbiota and consequences for the host. Pharmacological Research 68: 95-107.

De Lange CFM, Sauer WC, Mosenthin R and Souffrant WB (1989). The effect of feeding different protein-free diets on the recovery and amino acid composition of endogenous protein collected from the distal ileum and feces in pigs. Journal of Animal Science 67: 746-754.

DiLorenzo M, Bass J and Krantis A (1995). An intraluminal model of necrotizing enterocolitis in the developing neonatal piglet. Journal of Pediatric Surgery 30: 1138-1142.

Engemann A, Focke C and Humpf HU (2013). Intestinal formation of $\mathrm{N}$-nitroso compounds in the pig cecum model. Journal of Agricultural and Food Chemistry 61: 998-1005. 
Erickson RH and Kim YS (1990). Digestion and absorption of dietary protein. Annual Reviews of Medicine 41: 133-139.

Fairbrother JM, Nadeau E and Gyles CL (2005). Escherichia coli in postweaning diarrhea in pigs: an update on bacterial types, pathogenesis, and prevention strategies. Animal Health Research Reviews 6: 17-39.

Fontaine J, Zimmer U, Moughan PJ and Rutherfurd SM (2007). Effect of heat damage in an autoclave on the reactive lysine contents of soy products and corn distillers dried grains with solubles. Use of the results to check on lysine damage in common qualities of these ingredients. Journal of Agricultural and Food Chemistry 55: $10737-$ 10743.

Ganapathy V (2012). Protein digestion and absorption. In: Johnson LR, Gishan FK, Kaunitz, Merchant JL, Said HM, and Wood JD (eds) Physiology of the Gastrointestinal Tract, 5th edn, Elsevier Academic Press, San Diego, pp. 1595-1623.

Gehring CK, Bedford MR, Cowieson AJ and Dozier WA (2012). Effects of corn source on the relationship between in vitro assays and ileal nutrient digestibility. Poultry Science 91: 1908-1914.

Geypens B, Claus D, Evenepoel P, Hiele M, Maes B, Peeters M, Rutgeerts P and Ghoos Y (1997). Influence of dietary protein supplements on the formation of bacterial metabolites in the colon. Gut 41: 70-76.

González-Vega JC, Kim BG, Htoo JK, Lemme A and Stein HH (2011). Amino acid digestibility in heated soybean meal fed to growing pigs. Journal of Animal Science 89: 3617-3625.

Govers MJAP, Gannon NJ, Dunshea FR, Gibson PR and Muir JG (1999). Wheat bran affects the site of fermentation of resistant starch and luminal indexes related to colon cancer risk: a study in pigs. Gut 45: 840-847.

Hamer HM, Jonkers D, Venema K, Vanhoutvin S, Troost FJ and Brummer RJ (2008). Review article: the role of butyrate on colonic function. Alimentary Pharmacology and Therapeutics 27: 104-119.

Heo JM, Kim JC, Hansen CF, Mullan BP, Hampson DJ and Pluske JR (2008). Effects of feeding low protein diets to piglets on plasma urea nitrogen, faecal ammonia nitrogen, the incidence of diarrhea and performance after weaning. Archives of Animal Nutrition 62: 343-358.

Heo JM, Kim JC, Hansen CF, Mullan BP, Hampson DJ and Pluske JR (2009). Feeding a diet with decreased protein content reduces indices of protein fermentation and the incidence of postweaning diarrhea in weaned pigs challenged with an enterotoxigenic strain of Escherichia coli. Journal of Animal Science 87: 2833-2843.

Heo JM, Opapeju FO, Pluske JR, Kim JC, Hampson DJ and Nyachoti CM (2012). Gastrointestinal health and function in weaned pigs: a review of feeding strategies to control post-weaning diarrhoea without using in-feed antimicrobial compounds. Journal of Animal Pbysiology and Animal Nutrition 97, 207-237.

Heo JM, Kim JC, Yoo J and Pluske JR (2015). A between-experiment analysis of relationships linking dietary protein intake and postweaning diarrhea in weanling piglets under conditions of experimental infection with an enterotoxigenic strain of Escherichia coli. Animal Science Journal 86: 286-293.

Hermes RG, Molist F, Ywazaki M, Nofrarias M, Gomez De Segura A, Gasa J and Perez JF (2009). Effect of dietary level of protein and fiber on the productive performance and health status of piglets. Journal of Animal Science 87: 3569-3577.

Hughes R, Magee EAM and Bingham S (2000). Protein degradation in the large intestine: relevance to colorectal cancer. Current Issues in Intestinal Microbiology 1: 51-58.

Hughes R, Kurth MJ, McGilligan V, McGlynn H and Rowland I (2008). Effect of colonic bacterial metabolites on Caco-2 cell paracellular permeability in vitro. Nutrition and Cancer 60: 259-266.

Isaacson R and Kim HB (2012). The intestinal microbiome of the pig. Animal Health Research Reviews 13: 100-109.

Jha R and Berrocoso JFD (2016). Dietary fiber and protein fermentation in the intestine of swine and their interactive effects on gut health and on the environment: A review. Animal Feed Science and Technology 212: 18-26.
Jensen MT, Cox RP and Jensen BB (1995). Microbial production of skatole in the hindgut of pigs given different diets and its relation to skatole deposition in backfat. Animal Science 61: 293-304.

Jha R and Berrocoso JFD (2016). Dietary fiber and protein fermentation in the intestine of swine and their interactive effects on gut health and on the environment: a review. Animal Feed Science and Technology 212: 18-26.

Kambashi B, Boudry C, Picron P and Bindelle J (2014). Forage plants as an alternative feed resource for sustainable pig production in the tropics: a review. Animal 8: 1298-1311.

Kikugawa $\mathrm{K}$ and Kato T (1988). Formation of a mutagenic diazoquinone by interaction of phenol with nitrite. Food and Chemical Toxicology 26: 209-214.

Kim HB, Borewicz K, White BA, Singer RS, Sreevatsan S, Tu ZJ and Isaacson RE (2011a) Longitudinal investigation of the age-related bacterial diversity in the feces of commercial pigs. Veterinary Microbiology 153: 124-133.

Kim JC, Heo JM, Mullan BP and Pluske JR (2011b) Efficacy of a reduced protein diet on clinical expression of post-weaning diarrhoea and life-time performance after experimental challenge with an enterotoxigenic strain of Eschericbia coli. Animal Feed Science and Technology 170: 222-230.

Kim MH, Kang SG, Park JH, Yanagisawa M and Kim CH (2013). Short-chain fatty acids activate GPR41 and GPR43 on intestinal epithelial cells to promote inflammatory responses in mice. Gastroenterology 145: 396-406.

Knuckles BE, Kuzmicky DD, Gumbmann MR and Betschart AA (1989). Effect of myoinositol phosphate esters on in vitro and in vivo digestion of protein. Journal of Food Science 54: 1348-1350.

Kröger S, Pieper R, Schwelberger HG, Wang J, Villodre Tudela C, Aschenbach JR, Van Kessel AG and Zentek J (2013). Diets high in heat-treated soybean meal reduce the histamine-induced epithelial response in the colon of weaned piglets and increase epithelial catabolism of histamine. PLOS ONE 8: e80612.

Kröger S, Pieper R, Aschenbach JR, Martin L, Liu P, Rieger J, Schwelberger HG, Neumann K and Zentek J (2015). Effects of high levels of dietary zinc oxide on ex vivo epithelial histamine response and investigations on histamine receptor action in the proximal colon of weaned piglets. Journal of Animal Science 93: 5265-5272.

Kuley E, Balıkcı E, Özoğul I, Gökdogan S and Özoğul F (2012). Stimulation of cadaverine production by food borne pathogens in the presence of Lactobacillus, Lactococcus, and Streptococcus spp. Journal of Food Science 77: 650-658.

Leschelle X, Robert V, Delpal S, Mouille B, Mayeur C, Martel P and Blachier F (2002). Isolation of pig colonic crypts for cytotoxic assay of luminal compounds: effects of hydrogen sulfide, ammonia, and deoxycholic acid. Cell Biology and Toxicology 18: 193-203.

Lewis MC, Inman CF, Patel D, Schmidt B, Mulder I, Miller B, Gill BP, Pluske J, Kelly D, Stokes CR and Bailey M (2012). Direct experimental evidence that early-life farm environment influences regulation of immune responses. Pediatric Allergy and Immunology 23: 265-269.

Lin J (2004). Too much short chain fatty acids cause neonatal necrotizing enterocolitis. Medical Hypotheses 62: 291-293.

Liu Y, Ipharraguerre IR and Pettigrew JE (2013). Digestive physiology of the pig symposium: potential applications of knowledge of gut chemosensing in pig production. Journal of Animal Science 91: 19821990.

Looft T, Allen HA, Cantarel BL, Levine UY, Bayles DO, Alt DP, Henrissat B and Stanton TB (2014). Bacteria, phages and pigs: the effects of in-feed antibiotics on the microbiome at different gut locations. ISME Journal 8: 1566-1576.

Mann E, Schmitz-Esser S, Zebeli Q, Wagner M, Ritzmann M and Metzler-Zebeli BU (2014). Mucosa-associated bacterial microbiome of the gastrointestinal tract of weaned pigs and dynamics linked to dietary calcium-phosphorus. PLoS ONE 9: e86950.

Merrifield CA, Lewis M, Berger B, Cloarec O, Heinzmann SS, Charton F, Krause L, Levin NS, Duncker S, Mercenier A, Holmes E, 
Bailey M and Nicholson JK (2015). Neonatal environment exert a sustained influence on the development of the intestinal microbiota and metabolic phenotype. ISME Journal 10, 145-157.

Moughan PJ, Ravindran V and Sorbara JOB (2014). Dietary protein and amino acids - Consideration of the undigestible fraction. Poultry Science 93: 1-11.

Mulder IE, Schmidt B, Lewis M, Delday M, Stokes CR, Bailey M, Aminov RI, Gill BP, Pluske JR, Mayer CD and Kelly D (2011). Restricting microbial exposure in early life negates the immune benefits associated with gut colonization in environments of high microbial diversity. PLoS ONE 6: e28279.

Nyachoti CM, Omogbenigun FO, Rademacher M and Blank G (2006). Performance responses and indicators of gastrointestinal health in early-weaned pigs fed low- protein amino acid-supplemented diets. Journal of Animal Science 84: 125-134.

Opapeju FO, Krause DO, Payne RL, Rademacher M and Nyachoti CM (2009). Effect of dietary protein level on growth performance, indicators of enteric health, and gastrointestinal microbial ecology of weaned pigs induced with postweaning colibacillosis. Journal of Animal Science 87: 2635-2643.

Pieper R, Kröger S, Richter JF, Wang J, Martin L, Bindelle J, Htoo JK, von Smolinski D, Vahjen W, Zentek J and Van Kessel AG (2012). Fermentable fiber ameliorates fermentable protein-induced changes in microbial ecology, but not the mucosal response, in the colon of piglets. Journal of Nutrition 142: 661-667.

Pieper R, Boudry C, Bindelle J, Vahjen W and Zentek J (2014). Interaction between dietary protein content and the source of carbohydrates along the gastrointestinal tract of weaned piglets. Arcbives of Animal Nutrition 68: 263-280.

Pieper R, Vahjen W and Zentek J (2015). Dietary fibre and crude protein: impact on gastrointestinal microbial fermentation characteristics and host response. Animal Production Science 55: $1367-1375$.

Pietrzak T, Schad A, Zentek J and Mosenthin R (2002). Biogene amine in der Tierernährung: Entstehung, Stoffwechsel und physiologische Aspekte. Übersichten zur Tierernäbrung 31: 37-64.

Plöger S, Stumpff F, Penner GB, Schulzke JD, Gäbel G, Martens H, Shen Z, Günzel D and Aschenbach JR (2012). Microbial butyrate and its role for barrier function in the gastrointestinal tract. Annals of the New York. Academy of Sciences 1258: 52-59.

Prohaszka L and Baron F (1980). The predisposing role of high dietary protein supplies in enteropathogenic Escherichia coli infections in weaned pigs. Zentralblatt Veterinarmedizin 27: 222-232.

Rajendran S and Prakash V (1993). Kinetics and thermodynamics of the mechanism of interaction of sodium phytate with alpha-globulin. Biochemistry 32: 3474-3478.

Richter JF, Pieper R, Zakrzewski SS, Günzel D, Schulzke JD and Van Kessel AG (2014). Diets high in fermentable protein and fibre alter tight junction protein composition with minor effects on barrier function in piglet colon. British Journal of Nutrition 111: 10401049.

Rist VTS, Weiss E, Eklund M and Mosenthin R (2013). Impact of dietary protein on microbiota composition and activity in the gastrointestinal tract of piglets in relation to gut health: a review. Animal 7: 1067-1078.

Rojas OJ and Stein HH (2013). Concentration of digestible, metabolizable, and net energy and digestibility of energy and nutrients in fermented soybean meal, conventional soybean meal, and fish meal fed to weanling pigs. Journal of Animal Science 91: 4397_ 4405.
Seiler N and Raul F (2007). Polyamines and the intestinal tract. Critical Reviews in Clinical Laboratory Sciences 44: 365-411.

Selle PH, Cowieson AJ, Cowieson NP and Ravindran V (2012). Protein-phytate interactions in pig and poultry nutrition: a reappraisal. Nutrition Research Reviews 25: 1-17.

Slezak K, Hanske L, Loh G and Blaut M (2013). Increased bacterial putrescine has no impact on gut morphology and physiology in gnotobiotic adolescent mice. Beneficial Microbes 4: 253-266.

Smith EA and Macfarlane GT (1998). Enumeration of amino acid fermenting bacteria in the human large intestine: effects of $\mathrm{pH}$ and starch on peptide metabolism and dissimilation of amino acids. FEMS Microbiology Ecology 25: 355-368.

Souffrant WB (2001). Effect of dietary fibre on ileal digestibility and endogenous nitrogen losses in the pig. Animal Feed Science and Technology 90: 93-102.

Stein HH, Fuller MF, Moughan PJ, Sève B, Mosenthin R, Jansman AJM and De Lange CFM (2007). Definition of apparent, true, and standardized ileal digestibility of amino acids in pigs. Livestock Science 109: 282-285.

Stokes CR, Miller BG and Bourne FJ (1987). Animal models of food sensitivity. Food Allergy and Intolerance 2: 286-300.

Stumpff F, Lodemann U, Van Kessel AG, Pieper R, Klingspor S, Wolf K, Martens H, Zentek J and Aschenbach JR (2013). Effects of dietary fibre and protein on urea transport across the cecal mucosa of piglets. Journal of Comparative Physiology B 183: 1053-1063.

Torres AG (2009). The cad locus of Enterobacteriaceae: more than just lysine decarboxylation. Anaerobe 15: 1-6.

Ulven T (2012). Short-chain free fatty acid receptors FFA2/GPR43 and FFA3/GPR41 as new potential therapeutic targets. Frontiers in Endocrinology 3: 111.

Villodre Tudela C, Boudry C, Stumpff F, Aschenback JR, Vahjen W, Zentek J and Pieper R (2015). Down-regulation of monocarboxylate transporter 1 (MCT1) gene expression in the colon of piglets is linked to bacterial protein fermentation and pro-inflammatory cytokine-mediated signalling. British Journal of Nutrition 113: 610-617.

Villodre Tudela C, Tedin K, Zentek J and Pieper R (2016). Influence of bacterial metabolites on barrier function and pro-inflammatory signalling in epithelial cells in vitro. Proceedings of the Society of Nutrition Physiology 25: 23.

Vinolo MAR, Rodrigues HG, Nachbar RT and Curi R (2011). Regulation of inflammation by short chain fatty acids. Nutrients 3: 858-876.

Wallace JL, Ferraz JG and Muscara MN (2012). Hydrogen sulfide: an endogenous mediator of resolution of inflammation and injury. Antioxidants and Redox Signaling 17: 58-67.

Wellock IJ, Fortomaris PD, Houdijk JGM and Kyriazakis I (2006). The effect of dietary protein supply on the performance and risk of post-weaning enteric disorders in newly weaned pigs. Animal Science 82: 327-335.

Wellock IJ, Fortomaris PD, Houdijk JGM and Kyriazakis I (2008). Effects of dietary protein supply, weaning age and experimental enterotoxigenic Escherichia coli infection on newly weaned pigs: health. Animal 2: 834-842.

Wikoff WR, Anfora AT, Liu J, Schultz PG, Lesley SA, Peters EC and Siuzdak G (2009). Metabolomics analysis reveals large effects of gut microflora on mammalian blood metabolites. Proceedings of the National Academy of Sciences 106: 3698-3703.

Willing B and Van Kessel AG (2010). Host pathways for recognition: establishing gastrointestinal microbiota as relevant in animal health and nutrition. Livestock Science 133: 82-91. 